\title{
A perspectiva do serviço social sobre adoção de crianças e adolescentes por casais homoafetivos
}

\section{The social service's perspective on adoption of childrenand adolescents by homoaffective couples}

\author{
Beatriz da Silva Oliveira \\ Bacharel em Serviço Social pela Universidade UniRedentor Instituição: \\ Universidade UniRedentor Local de trabalho (a de vínculoatualmente, \\ seja ela vínculo acadêmico ou profissional): UniversidadeUniRedentor \\ Endereço: BR-356, 25 - Pres. Costa e Silva, Itaperuna - RJ, 28300-000E- \\ mail: beatrizoliveirasilva54@gmail.com
}

\section{RESUMO}

O presente artigo tem por objetivo apontar os desafios do trabalho do assistente social no processo de adoção de crianças e adolescentes por casais homoafetivos na sociedade brasileira, além de compreender as dificuldades dos casais homoafetivos encontradas no processo de adoção e apresentar a produção científica do Serviço Social sobre o processo de adoção no Brasil por casais homoafetivos. A metodologia utilizada foi a pesquisa bibliográfica, tendo como universo de pesquisa a produção científica dos Congresso Brasileiros de Assistentes Sociais (CBAS) de 2016 e 2019 e Encontro Nacional de Pesquisadores do Serviço Social (ENPESS) de 2016 e 2018, a qual abordasse a adoção homoafetiva. Os resultados alcançados estão relacionados à necessidade de conhecimento desses casais que são vítimas de estereótipos e discriminação social, bem como das legislações vigentes e seus impactos na superação das realidades vivenciadas por esses sujeitos.

Palavras-chave: família homoafetiva, adoção homoafetiva, produção cientifica serviço social.

\section{ABSTRACT}

This article aims to point out the challenges of the work of social workers in the process of adoption of children and adolescents by same-sex couples in Brazilian society, in addition to understanding the difficulties of same-sex couples encountered in the adoption process and presenting the scientific production of Social Work on the adoption process in Brazil by same-sex couples. The methodology used was bibliographic research, having as research universe the scientific production of the Brazilian Congress of Social Workers (CBAS) in 2016 and 2019 and the National Meeting of Social Work Researchers (ENPESS) in 2016 and 2018, which addressed the adoption homoaffective. The results achieved are related to the need for knowledge of these couples who are victims 
of stereotypes and social discrimination, as well as current legislation and itsimpacts on overcoming the realities experienced by these subjects.

Keywords: homoaffective family, homoaffective adoption, scientific productionsocial service.

\section{INTRODUÇÃO}

Ao pensarmos sobre o processo de adoção, destacamos inicialmente os avanços pertinentes na legislação, atualmente, os casais homoafetivos deparam-se durante o processo de adoção com entraves por parte da sociedade. Esses percalços variam desde o equívoco de considerarem incapazes de cuidar de uma criança ou que irão influenciar na orientação sexual dela e que poderão sofrer preconceitos por ser filho de homoafetivos.

Diante dos inúmeros desafios nos debruçamos a pesquisar sobre os desafios do trabalho do assistente social no processo de adoção de crianças e adolescentes por casais homoafetivos no contexto da sociedade brasileira, tendo como objetivo principal apontar os desafios do trabalho do assistente social no processo de adoção de crianças e adolescentes por casais homoafetivos na sociedade brasileira, além de identificar os mecanismos legais para os casais homoafetivos que desejam adotar no Brasil, compreender os empecilhos ou desafios que os casais homoafetivos encontram no processo de adoção e relatar a atuação do assistente social no processo de adoção no Brasil por casais homoafetivos.

Com o intuito de atingir os objetivos propostos utilizamos o método qualitativo, por meio da pesquisa bibliográfica, como ponto de partida na construção efetiva da pesquisa, isto é, após a escolha de um assunto que é necessário criar uma revisão bibliográfica do assunto. Ao consideramos a pesquisa bibliográfica, tivemos como o universo de pesquisa a produção cientifica dos Congresso Brasileiro de Assistentes Sociais (CBAS) de 2016 e 2019 e do Encontro Nacional de Pesquisadores de Serviço Social (ENPESS) de 2016 e 2018, totalizando seis trabalhos, a fim de verificar como o tema adoção homoafetivo é abordado pelo Serviço Social. 


\section{A ADOÇÃO HOMOAFETIVA SOB A PERSPECTIVA DO SERVIÇO SOCIAL}

Desejando me aproximar dos objetivos definidos, optamos pela pesquisa bibliográfica, considerando inicialmente realizar uma revisão da literatura sobrea adoção homoafetiva, tendo como universo de pesquisa a produção recentetrazidas nos encontros significativos da categoria a destacar o CongressoBrasileiro de Assistentes Sociais (CBAS) e o Encontro Nacional de Pesquisadores de Serviço Social (ENPESS).

Ao consideramos nosso universo de pesquisa, consideramos a produção cientifica do Serviço Social sobre a temática priorizando os trabalhos aprovados nos CBAS realizados em 2016 e 2019 e nos ENPESS de 2016 e 2018. O recorte deve-se a relevância dos eventos, seu caráter científico e acadêmico, constituindo-se em espaços privilegiados para intercâmbio de pesquisas e produções acadêmicas.

O que se pretende analisar nos artigos é a evolução do conceito de família até a contemporaneidade com a inserção da família homoafetiva, as dificuldades para os casais homoafetivos e a atuação e intervenção do assistente social no processo de adoção de crianças e adolescentes por casais homoafetivos.

Quadro 1 - Trabalho apresentados nos CBAS e ENPESS:

\begin{tabular}{|c|c|}
\hline Evento/ Ano & Titulo \\
\hline CBAS-2016. & Família homoafetiva: conhecendo trajetórias da adoção. \\
\hline ENPESS- 2016 & $\begin{array}{l}\text { Adoção por casais homoafetivos: uma visão sobre o conceito de } \\
\text { família. }\end{array}$ \\
\hline ENPESS- 2018. & $\begin{array}{c}\text { Novos arranjos familiares: compromisso ético político na intervenção } \\
\text { profissional. }\end{array}$ \\
\hline ENPESS-2018. & $\begin{array}{l}\text { Família e homoparentalidade no ordenamento jurídico brasileiro } \\
\qquad(2009-2017)\end{array}$ \\
\hline CBAS- 2019. & Famílias homoafetivas: reconhecer direitos e superar limites. \\
\hline CBAS- 2019 & A intervenção da/o assistente social no processo de adoção. \\
\hline
\end{tabular}

Fonte: Elaboração pelos autores

A fim de mostrar os resultados científicos do Serviço Social sobre a adoção homoafetiva que encontramos e selecionamos, analisamos todos os artigos que foram expostos anteriormente a partir de três eixos de analises, a 


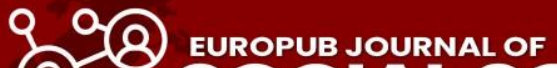

saber: Família, família homoafetiva; Adoção, adoção homoafetiva; e Atuação doServiço Social.

\section{ANÁLISE SOBRE CATEGORIA FAMÍLIA E FAMÍLIA HOMOAFETIVA}

Moraes (2016), na trajetória histórica sobre a concepção de família evidencia a família na tradição romana que se concentrou na figura do pai, pois representava a hierarquia superior da casa, isto é, ele exerceu poder para mulheres, crianças e escravos. Nesta família ocidental, a família patriarcal, o pai era a única e responsável exclusivamente da propriedade da família, representava o domínio de sua família. E nesse período, a Igreja Católica tinha uma grande influência na concepção da família, uma vez que considerava famílias sob o modelo da Sagrada Família.

Em 1988, a Constituição Federal Brasileira inseriu a entidade familiar, no entanto, com características de uma família nuclear, que ainda representava a forma patriarcal, muito diferente da família nos anos 20 , porque com a regulação do divórcio poderia haver mudanças na constituição de família instituída. O divórcio ocasionou as famílias monetárias, e igualdade sexual, no entanto, vale a pena mencionar que a sociedade patriarcal ainda é refletida na sociedade de hoje.

Segundo Silva e Dionízio (2018), na atualidade, deve-se compreender a realidade do arranjo familiar e suas as reais necessidades para 0 melhor aproveitamento dos recursos sociais disponíveis e contribui para a construção de políticas públicas, projetos, programas e serviços na rede de assistência social.

Para Cagliari e Rodrigues (2016), a família homoafetiva é uma união estável de pessoas do mesmo sexo. Embora a possibilidade de estruturação e expressividade familiar esteja aumentando nas atuais circunstâncias, as famílias que fogem de padrões socialmente reconhecidos e aceitos são estigmatizadas e se tornaram alvo de preconceitos nas sociedades tradicionais e conservadorasda história. 
Barros, Freitas e Barros (2018), afirmam que a família homoafetiva ao longo do tempo vem aumentando de acordo com os estudos do IBGE. Mesmo com a legalização do casamento de pessoas homoafetivas, eles ainda lutam pelo direito da adoção sendo necessário que os profissionais da área de direito compreendam esse novo arranjo familiar.

Mediante ao que foi exposto é possível observar que as autoras trazem conceituação de família e família homoafetiva e essas conceituações são convergentes. Concordo com a colocação das autoras Cagliari e Rodrigues (2016), pois é evidente que as famílias homoafetivas ainda têm muito a conquistar para terem respeito e legislações voltadas para ao combate ao preconceito.

Registramos que autoras Fontonele, Miranda e Silva (2019), não conceituam em seu artigo a definição de família e família homoafetiva.

\section{AS DIFICULDADES PARA A ADOÇÃO DOS CASAIS HOMOAFETIVOS}

As autoras Barros, Freitas e Barros (2018), mencionam que devido à dificuldade desses casais adotarem, muitas optam pela reprodução assistida que foi assegurado pelo Conselho de Medicina por meio da Resolução 2.013/2013, porém eles não podiam registrar seus filhos. Posteriormente, em 14 de março de 2016, o Conselho Nacional de Justiça editou um provimento ( $\left.\mathrm{N}^{\circ} 52\right)$, foi concebido o direito desses casais registrarem seus filhos.

Outra possibilidade é a adoção monoparental, onde somente um adota a criança e o outro não terá vínculos civis com essa criança. Isso devido à falta de legislações que permite a adoção por esses casais e o posicionamento dos juízes baseados em seus valores morais.

Em conformidade Oliveira e Melo (2016), destacam a importância de reconhecer a variedade de regulamentos familiares e tratá-los dentro da sociedade. Neste contexto, o Estado deve ser invocado na responsabilidade do seu cumprimento no reconhecimento e nos requisitos de todas as famílias. O Estado, na sua secularização, não pode permitir a interferência religiosa e nem atender aos requisitos de certos grupos sociais. 
Segundo Cagliari e Rodrigues (2016), o não reconhecimento da família homoafetiva e o desenvolvimento psicossocial da criança e do adolescente atrapalham a legitimidade e a aceitação social dessas famílias e podem prejudicar o processo de adoção ao expor os preconceitos e receios de diversos profissionais que permeiam todo o processo.

Ao complementar Oliveira e Melo (2016), afirmam que mesmo que os direitos sociais sejam aprimorados, ainda é possível verificar os preconceitos existentes contra pessoas que não se enquadram nas normas de diferentes padrões culturais. Embora muitas mudanças tenham ocorrido na família nuclear, uma cultura conservadora ainda existe fortemente, levando a um aumento da violência contra as pessoas LGBT.

As autoras Fontonele, Miranda e Silva (2019); Moraes (2019) e Silva e Dionízio (2019), em seus textos não abordam sobre as dificuldades para a adoção por casais homoafetivos.

Em virtude dos fatos mencionados sobre o que as autoras apresentam podemos notar que são diversas as dificuldades que os casais homoafetivos enfrentam no processo de adoção de crianças e adolescentes devido a não reconhecimento dessa família por parte da sociedade e Estado e a falta de legislação que deem a essas famílias o direito de adotar. 


\section{REFERÊNCIAS}

BRASIL. Lei Federal o 8.069, de 13 de junho de 1990. Brasília: 1990. Estatuto da Criança e do Adolescente. Disponível em:

<http://www.planalto.gov.br/ccivil_03/leis/L8069.htm>. Acesso em:15/03/2021 às 09:00.

BARROS, Maria Izabel Valença. FREITAS, Rita de Cássia Santos. BARROS, Nívia Valença. Família e homoparentalidade no ordenamento jurídico brasileiro (2009-2017). XVI ENPESS. Vitória- ES, 2018

CAGLIARI, Gabriela Amaro. RODRIGUES, Teresinha de Fátima. Família Homoafetiva: conhecendo trajetórias da adoção. $15^{\circ}$ CBAS, 2016

FONTONELE, Roseane da Conceição. MIRANDA, Luana Faustino. SILVA, Luane Gomes da Silva. A intervenção da/o assistente social no processo de adoção. $16^{\circ} \mathrm{CBAS}, 2019$

MORAES, Natyéllen Casimiro De. Adoção por casais homoafetivos: uma visão sobre o conceito de família. XV ENPESS, 2016

OLIVEIRA, Carolina Sampaio de Sá. MELO, Ferdinando Santos de. Famílias homoafetivas: reconhecer direitos e superar limites. $16^{\circ} \mathrm{CBAS}, 2019$

SILVA, Ana Cláudia Fontes da. DIONÍZIO, Silvia Helena dos Santos. Novos arranjos familiares: compromisso ético político na intervenção profissional. XVI ENPESS. Vitória- ES, 2018. 